\title{
Evaluation of Propranolol and Quinidine in the Treatment of Quinidine-Resistant Arrhythmias
}

WILLIAM J. FORS, Jr., MD

CONDON R. VANDERARK, MD

ERNEST W. REYNOLDS, Jr., MD, FACC

Ann Arbor, Michigan
From the University of Michigan Medical Center, Ann Arbor, Mich. This work was supported by Grants from the Michigan Heart Association and U.S. Public Health Service, National Institutes of Health HE 07406-05. Manuscript received October 3 , 1969, accepted February 6, 1970.

Address for reprints: Ernest W. Reynolds, Jr., MD, University of Michigan Medical Center, Ann Arbor, Mich. 48104.
Combining propranolol and quinidine should improve the antiarrhythmic action of quinidine by blocking beta adrenergic receptors, an action helpful in cases of arrhythmias associated with anesthetic agents, digitalis and stress. To test this hypothesis, 60 patients with paroxysmal arrhythmias resistant to quinidine and 17 with chronic atrial fibrillation were given propranolol alone or in combination with quinidine (or procainamide) and followed up 1 to 17 months. Patients with severe aortic valve disease, severe mitral insufficiency, acute myocardial infarction or obstructive airway diseases were excluded from this study. The condition of 13 of 19 patients with paroxysmal atrial or nodal tachycardia was improved. In paroxysmal ventricular tachycardia combined therapy or propranolol alone was effective in 11 of 14 patients. Paroxysmal atrial flutter or fibrillation was suppressed in 11 of 16 patients, with a 75 percent or greater reduction in attacks. Prophylaxis of chronic atrial fibrillation terminated by drugs or by electroshock was effective in 9 of 11 patients (15 trials) followed up for 7 months. Sustained atrial fibrillation was terminated with propranolol, 40 to $160 \mathrm{mg}$, and quinidine sulfate, 1.2 to $1.6 \mathrm{~g} /$ day, in 41 percent of patients, a result no better than with propranolol alone. Propranolol slowed the ventricular rate in normal sinus rhythm as well as in atrial fibrillation and flutter. Significant slowing, although it was less in magnitude, occurred with the combination of propranolol and quinidine. It is concluded that propranolol potentiates quinidine and allows effective prophylaxis of atrial, nodal and ventricular arrhythmias in quinidine-resistant patients. Diarrhea was the only side effect peculiar to the combination of drugs.

With the introduction of the beta adrenergic blocking agent, dichloroisoproterenol, several reports appeared describing its antiarrhythmic effects in catecholamine-induced cardiac arrhythmias, ${ }^{1-4}$ but no important clinical interest was aroused until Lucchesi and Hardman ${ }^{5}$ showed that dichloroisoproterenol reversed ouabain-induced ventricular arrhythmias. This was the first suggestion that this drug possessed antiarrhythmic properties that were not dependent on specific receptor inhibition. Later pronetholol $^{6,7}$ and propranolol ${ }^{8}$ were also shown to have antiarrhythmic properties that were not dependent on specific receptor inhibition.

Davis and Temte ${ }^{9}$ showed that doses of propranolol in excess of those required to produce beta receptor blockade caused a decrease in upstroke velocity and overall height of the action potential of Purkinje fibers. In addition, propranolol raised the membrane 
TABLE I

\section{Categories of Patients Studied}

\begin{tabular}{ll}
\hline & $\begin{array}{c}\text { no. of } \\
\text { Patients } \\
\text { (Trials) }\end{array}$ \\
\hline Prophylaxis & \\
Paroxysmal atrial or nodal tachycardia & $19(19)$ \\
Paroxysmal ventricular tachycardia & $14(14)$ \\
Paroxysmal atrial fibrillation or flutter & $16(16)$ \\
Recurrent atrial fibrillation or flutter & $11(15)$ \\
Termination & $17(21)$ \\
Atrial fibrillation or flutter & $77(85)$ \\
\hline Total &
\end{tabular}

threshold potential so that the fiber had to recover more fully before becoming excitable. The most striking effect was the lack of local, nonpropagated responses and decremental conduction. The only responses that could be elicited by premature excitation in the presence of propranolol were relatively large with rapid velocity of the upstroke. These effects of propranolol on Purkinje fibers are similar to the effects of quinidine as studied by Weidmann ${ }^{10}$; however, in therapeutic doses propranolol has little effect on ventricular muscle. ${ }^{9}$ Propranolol is also unlike quinidine in that the duration of the action potential and the effective refractory period are shortened, whereas quinidine lengthens both.

The beneficial effect of the combination of propranolol and quinidine may reflect the ability to obtain both the beta adrenergic receptor inhibition known to be helpful in the catecholamine-induced arrhythmias, the nonspecific effect of propranolol in preventing local nonpropagated responses and the additive effects of both drugs in decreasing spontaneous diastolic depolarization and raising the threshold of excitability. In addition, propranolol has a salutory effect by slowing conduction through the atrioventricular $(\mathrm{A}-\mathrm{V})$ node. This action, previously reserved for digitalis, is useful in protecting the ventricles from a rapid response during atrial flutter or fibrillation.

\section{Case Material}

The use of propranolol combined with quinidine was studied during 85 clinical trials in 77 patients in the 5 categories shown in Table $I$. In addition, changes in ventricular rate in atrial fibrillation and sinus tachycardia were compared in 40 patients given propranolol alone and 38 patients receiving propranolol combined with quinidine.

\section{Methods}

The patients were admitted to the hospital and continuously monitored with a recording cardiotachometer and a magnetic tape recorder. This provided a daily count of premature beats and attacks of abnormal rhythm as well as providing access to the electrocardiogram during rhythm disturbances by review of the magnetic tape. Details of this technique have been described in previous reports. ${ }^{11}$ This initial hospitalization was divided into a 24 hour placebo period and similar 24 hour periods while the patient received various test drugs. The drugs included quinidine alone and in combination with propranolol as* well as additional agents such as potassium, procainamide, Librium and digitalis. The patients were then given the most effective drug or drug combination as indicated by this screening procedure and followed up as outpatients. Long-term evaluation was bised on a comparison of the frequency of attacks, as noted on a report card kept by the patient, with the frequency of attacks before therapy. If long-term trials indicated failure of 1 drug, the patient was then given propranolol and quinidine for the rest of the study.

\section{Results}

Prophylaxis of paroxysmal atrial or A-V junctional (nodal) tachycardia: Paroxysmal atrial or nodal tachycardia was studied in 19 patients who had had this condition an average of 10.6 years. There were 4 patients with rheumatic heart disease, 4 with arteriosclerotic heart disease, 1 with carcinoma of the esophagus and 10 with no evidence of heart disease. Thirteen of the patients had atrial tachycardia, and 6 had nodal tachycardia confirmed by electrocardiogram. Prior unsuccessful therapy consisted of quinidine in 17 cases, digitalis in 13, propranolol in 8 , diphenylhydantoin in 3 , procainamide in 2, papaverine in 2, and antazoline, Valium ${ }^{\circledR}$, Vistaril ${ }^{\circledR}$, Librium ${ }^{\circledR}$ and potassium in 1 patient each. Table II shows the results obtained with propranolol alone and with propranolol combined with quinidine or procainamide. Thirteen of the 19 patients (68 percent) resistant to quinidine and other drugs were benefited by propranolol alone or in combination with quinidine or procainamide. Dosage ranged from 60 to $120 \mathrm{mg}$ of propranolol alone or 40 to $160 \mathrm{mg}$ of propranolol combined with 0.6 to $1.6 \mathrm{~g}$ of quinidine sulfate or its equivalent per day in divided doses every 6 to 8 hours. Procainamide was used in 1 patient in a dose of $1.5 \mathrm{~g} /$ day with $120 \mathrm{mg} /$ day of propranolol.

TABLE ॥

Results in the Prophylaxis of Paroxysmal Atrial and Nodal Tachycardia

\begin{tabular}{lcccc}
\hline \multicolumn{1}{c}{ Treatment } & $\begin{array}{c}\text { no. of } \\
\text { Patients }\end{array}$ & $\begin{array}{c}90 \%^{*} \\
\text { Effective }\end{array}$ & Improved & $\begin{array}{c}\text { Un- } \\
\text { improved }\end{array}$ \\
\hline Propranolol & 5 & 3 & 1 & 1 \\
Propranolol + quinidine & 13 & 5 & 3 & 5 \\
Propranolol + procainamide & 1 & 1 & 0 & 0 \\
$\quad$ Total & 19 & 9 & 4 & 6 \\
\hline
\end{tabular}

* Complete suppression or less than 10 percent residual attacks during therapy compared to the frequency of attacks during a control period. 
TABLE III

Clinical Trials in Paroxysmal Ventricular Tachycardia

\begin{tabular}{|c|c|c|c|c|c|c|}
\hline \multirow[b]{2}{*}{ Case no. } & \multicolumn{2}{|c|}{ Propranolol } & \multicolumn{2}{|c|}{$\begin{array}{c}\text { Propranalol }+ \\
\text { Quinidine }\end{array}$} & \multicolumn{2}{|c|}{$\begin{array}{l}\text { Propranolol + } \\
\text { Lidocaine or } \\
\text { Pronesty|(\$) }\end{array}$} \\
\hline & + & $=$ & + & $=$ & + & - \\
\hline \multicolumn{7}{|c|}{$\begin{array}{l}\text { Group I } \\
\text { Short duration }\end{array}$} \\
\hline 1 & 1 & & 1 & & & \\
\hline 2 & & & 1 & & & \\
\hline 3 & & 1 & & 1 & & $F$ \\
\hline 4 & & 1 & 1 & & & \\
\hline 5 & & & & & 1 & \\
\hline \multicolumn{7}{|l|}{ Group II } \\
\hline \multicolumn{7}{|c|}{ Long duration } \\
\hline 6 & & 1 & 1 & & & \\
\hline 7 & & 1 & & 1 & & $\mathbf{F}$ \\
\hline 8 & & 1 & 1 & & & \\
\hline 9 & & 1 & 1 & & & \\
\hline 10 & & 1 & 1 & & & \\
\hline 11 & 1 & & & & & $1^{*}$ \\
\hline 12 & 1 & & & & & \\
\hline 13 & & 1 & & 1 & & $\mathbf{F}$ \\
\hline 14 & & 1 & 1 & & & 1 \\
\hline \multicolumn{7}{|l|}{ Total } \\
\hline 14 patients & 3 & 9 & 8 & 3 & 1 & 2 \\
\hline 26 trials & 12 trials & & 11 trials & & 3 trials & \\
\hline
\end{tabular}

* The failure here was unrelated to a successful trial with propranolol alone over an earlier period but was complicated by a recent pulmonary embolus.

$+=$ effective $-=$ ineffective; $F=$ patients failing to respond to any combination listed.

Observations of effectiveness of therapy were made over 1 to 12 months (average 5 months).

Prophylaxis of paroxysmal ventricular tachycardia: The 14 patients with this disorder were divided into 2 groups based on the duration of the arrhythmia. Five patients had transient arrhythmias and, with 1 exception which ended fatally, the condition was self-limited. The average age of these patients was 48.8 years, and the paroxysmal ventricular tachycardia was present for an average of 5.6 days. The ventricular tachycardia was attributed to a complication of underlying arteriosclerotic heart disease in 4 instances. These complications were dissecting aneurysm, hemopericardium, digitalis excess and acute myocardial infarction. In the latter case, the patient was under treatment for recurrent ventricular tachycardia when acute myocardial infarction occurred, resulting in the only death in this group. The 9 patients with chronic ventricular tachycardia had an average age of 38.5 years, and ventricular tachycardia had been present for 12 to 96 months (average 41 months). Five of these patients had documented old myocardial infarction, and 4 had no overt heart disease.

All 14 test patients with paroxysmal ventricular tachycardia were considered resistant to quinidine treatment since, if prior screening indicated that quinidine was effective, the patient was excluded from this part of the study. Satisfactory management of the arrhythmia was achieved in all but 3 patients. Two of the patients not responding to therapy had no known heart disease and were 16 and 19 years of age, respectively. The documented attacks of ventricular tachycardia were obviously tolerated but would not respond to therapy. In the third failure, already referred to, the patient died of acute myocardial infarction while receiving therapy. The most effective therapy was the combination of propranolol and quinidine (Table III). Dosage ranged from 30 to $90 \mathrm{mg}$ of propranolol alone, or 15 to $160 \mathrm{mg}$ of propranolol combined with 0.6 to $2.6 \mathrm{~g}$ quinidine sulfate or equivalent per day in divided doses every 6 to 8 hours. The patients were followed up 2 to 17 months (average 6 months).

An example of the method of evaluation follows:
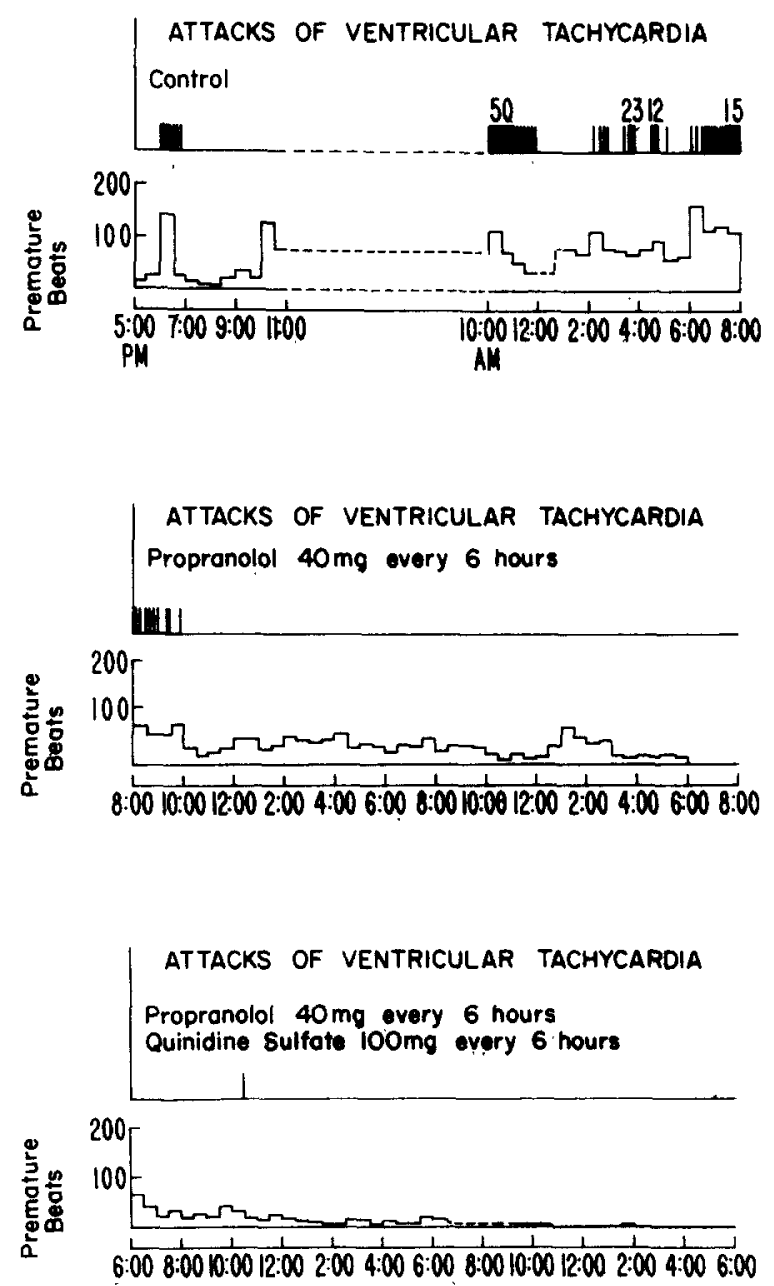

Figure 1. The frequency of attacks of ventricular tachy. cardia and ventricular premature beats are indicated for a control period, during therapy with propranolol alone and during therapy with propranolol and guinidine. Each bar corresponds to 1 attack of ventricular tachycardia. The numbers indicate frequency of attacks during the period indicated by a solid bar. The dashed lines indicate loss of data because of technical difficulties. Premature beats were counted for 30-minute periods, and the total for each period was plotted. 
A 56 year old white man sustained a myocardial infarction in October 1966. His hospitalization was complicated by intermittent ventricular tachycardia that could not be suppressed with procainamide. He was admitted during an attack of ventricular tachycardia which slowed but failed to terminate after intravenous administration of $5 \mathrm{mg}$ of propranolol; however, termination occurred spontaneously that same evening. Propranolol, $20 \mathrm{mg}$ orally every 8 hours, failed to prevent recurrence of ventricular tachycardia. The addition of procainamide also failed to prevent recurrent ventricular tachycardia and other episodes of nodal tachycardia. Quinidine, prostigmine, metaraminol and d-c cardioversion failed to terminate individual attacks, and quinidine failed to prevent recurrence after spontaneous termination. Figure 1 shows the number of attacks of ventricular tachycardia and premature beats during a 24 hour control period and 2 drug test periods. Increasing the dose of propranolol to $40 \mathrm{mg}$ every 6 hours eliminated all but 9 short episodes occurring 2 hours after the initial dose. The premature beat count was reduced from approximately $100 / 30 \mathrm{~min}$ during the control period to less than $50 / 30 \mathrm{~min}$. With the addition of quinidine, only 1 short attack of ventricular tachycardia occurred, and there was still further suppression of premature beats. This 3 day screening test suggested that the patient would respond to propranolol, $40 \mathrm{mg}$ every 6 hours; but the long-term outpatient studies indicated otherwise, and the patient was given this dose of propranolol combined with quinidine sulfate, $400 \mathrm{mg}$ every 6 hours. This resulted in only 6 episodes of ventricular tachycardia during the following 4 months. Changing to long-acting quinidine gluconate, $660 \mathrm{mg}$, and propranolol, $40 \mathrm{mg}$, each every 6 hours resulted in only 3 short episodes during the ensuing 4 months. On November 26, 1967, after a deer hunt, an attack of ventricular tachycardia occurred lasting 12 hours. An attempt to change to quinidine sulfate alone at this time resulted in intermittent but almost continuous attacks of ventricular tachycardia ; accordingly, the combination of quinidine and propranolol was restarted, and no further attacks occurred during the next 2 months. This combination was considered effective in suppressing repetitive ventricular tachycardia. This patient was followed up for 15 months.

Prophylaxis of paroxysmal atrial fibrillation or flutter: Sixteen patients with paroxysmal attacks of atrial fibrillation or flutter unaffected by digitalis or quinidine alone were given propranolol, 40 to $120 \mathrm{mg}$ alone ( 3 patients only), or 60 to $120 \mathrm{mg}$ in combination with quinidine sulfate, 0.6 to 1.3 $\mathrm{g}$ in divided doses. Five of these patients receiving combined therapy and 1 receiving propranolol alone had no further attacks (38 percent), and 5 patients had greater than a 75 percent reduction in frequency of attacks. Treatment failed in 5 patients, including 2 receiving propranolol alone. These patients were followed up 1 to 11 months (average 6 months).

Prophylaxis of atrial fibrillation or flutter following medical or electrical conversion: These subjects had chronic atrial fibrillation which was terminated after surgical correction of valvular heart disease or for other reasons. Eleven patients were given $60 \mathrm{mg}$ of propranolol plus $0.6 \mathrm{~g}$ of
TABLE IV

Termination Trials in Chronic Atrial Fibrillation

\begin{tabular}{lccc}
\hline & \multicolumn{3}{c}{ no. of Patients } \\
\cline { 2 - 4 } & Total & $\begin{array}{c}\text { With } \\
\text { Arrhythmia } \\
\text { Terminated }\end{array}$ & $\%$ \\
\hline Propranolol alone & 18 & 7 & 39 \\
Propranolol + quinidine & 17 & 7 & 41 \\
\hline
\end{tabular}

quinidine sulfate in divided doses every day and were followed up until atrial fibrillation or flutter returned or for up to 10 months (average 7 months). Eight of 11 patients (73 percent) remained in sinus rhythm. Patients not responding to treatment underwent a second conversion to normal rhythm and were followed up for a similar period, giving 15 trials with 9 patients (60 percent) maintaining sinus rhythm. The result in this small series compares favorably with the use of quinidine alone and was accomplished with a smaller dose of quinidine than has been recommended for this purpose.

Termination of atrial fibrillation or flutter: Previous studies in this laboratory ${ }^{11}$ and other studies $^{12,18}$ suggest that in approximately 80 percent of patients with chronic atrial flutter or fibrillation the arrhythmia will be converted to normal sinus rhythm by prior digitalization and the administration of $2.8 \mathrm{~g}$ of quinidine sulfate in a 24 hour period. Sokolow and Edgar ${ }^{13}$ have shown that increasing the dose of quinidine to raise the level higher than $8 \mu \mathrm{g} / \mathrm{ml}$ does not result in a much greater number of patients whose atrial fibrillation or flutter terminates. To learn if propranolol potentiates the action of quinidine, the dose of quinidine was reduced to half the amount used in the prior studies (1.2 to $1.6 \mathrm{~g} /$ day) and propranolol (40 to $160 \mathrm{mg} /$ day) was added. Conversion to normal sinus rhythm occurred in 41 percent of 17 patients on this regimen (Table IV). This was half the number of patients whose atrial fibrillation or flutter would be expected to terminate with administration of $2.8 \mathrm{~g}$ quinidine sulfate/day. This suggests that propranolol exerted no potentiating effect on the action of quinidine in terminating atrial fibrillation or flutter. When an additional 18 patients with atrial fibrillation or flutter were given propranolol in doses of 10 to $200 \mathrm{mg} /$ day to slow the ventricular rate, atrial fibrillation was terminated in 7 patients ( 39 percent). Thus, the results of propranolol combined with quinidine are no better than those with propranolol alone.

Effect of propranolol on $A-V$ conduction: An important salutory effect of propranolol is slowing of the ventricular response to atrial fibrillation or flutter, an action usually reserved for digitalis. Slowing the ventricular rate is particularly important during the quinidine termination of atrial fibrillation and flutter since the vagolytic effect of 
TABLE $V$

Change in Ventricular Rate During Trial*

\begin{tabular}{lcc}
\hline & $\begin{array}{c}\text { no. of } \\
\text { Patients }\end{array}$ & $\begin{array}{c}\text { Average } \\
\text { Rate Change } \\
\text { (beats/min) }\end{array}$ \\
\hline $\begin{array}{l}\text { Propranolol } \\
\text { Atrial fibrillation or flutter }\end{array}$ & 18 & -58 \\
$\quad \begin{array}{l}\text { Normal sinus rhythm } \\
\text { Sinus tachycardia }\end{array}$ & 17 & -23 \\
$\begin{array}{l}\text { Propranolol + quinidine } \\
\text { Atrial fibrillation or flutter }\end{array}$ & 5 & -38 \\
Normal sinus rhythm & 12 & -29.1 \\
\hline
\end{tabular}

* Slowing of the heart rate occurred in 74 patients; and 4 patients in the last category showed no change in heart rate. Since no patient exhibited an increase in rate, the rate change in each category is highly significant.

quinidine enhances $A-V$ conduction. This effect was studied using propranolol alone and with the addition of quinidine (Table V). Slowing of the ventricular rate was greater with propranolol alone than when combined with quinidine in normal sinus rhythm, sinus tachycardia, atrial fibrillation and atrial flutter; but significant slowing occurred with the combination of the 2 drugs. In no instance did the ventricular rate increase during administration of the propranolol or the combination, and there wcre no episodes of $1: 1$ conduction during atrial flutter.

Side effects: Patients having known contraindications to propranolol were excluded from the study. These contraindications included severe aortic valve disease, severe mitral insufficiency, asthma or infective bronchitis. Congestive heart failure was considered a relative contraindication, since if the arrhythmia was considered a sufficient threat to the patient's life, as in the case of ventricular tachycardia, propranolol was used in conjunction with digitalis and diuretic agents. In a patient having mitral stenosis and atrial fibrilla- tion with a rapid ventricular response, propranolol was administered even in the face of congestive failure since diastolic filling time could be increased by slowing the heart rate. This patient's condition did improve. Propranolol was not administered during low output states nor in shock. By observing these precautions there were few unexpected instances of congestive failure precipitated by propranolol. These instances were characterized by the appearance of a protodiastolic extra sound, weight gain, edema or a few fine moist rales. There were no instances of overt pulmonary edema. Sinus bradycardia was frequent and occasionally necessitated stopping the drug. Hypotension was rarely observed after the use of intravenous propranolol was discontinued early in the study.

The combination of propranolol and quinidine produced diarrhea in the majority of patients. This was transient, lasting only several days in most. It was controlled with Kaopectate ${ }^{\circledR}$ or Lomotil ${ }^{\oplus}$ when severe, and necessitated stopping the combination in a few patients. No instances of asystole, heart block or cardiac arrest occurred which could possibly be attributed to propranolol combined with quinidine. The single patient who died suddenly was admitted with preinfarction angina and found to have recurrent ventricular tachycardia. His condition did not respond to propranolol, $20 \mathrm{mg}$ every 6 hours; massive myocardial infarction developed and he died with ventricular fibrillation. Time did not permit trial with propranolol combined with quinidine. No other patients having acute myocardial infarction were given propranolol.

This selection of patients based on known contraindications to the several drugs used renders quantitative data regarding toxic and side effects valueless, but the study does indicate that no great danger exists if these drugs are used with these precautions in mind.

\section{References}

1. Gilbert JL, Lange G, Brooks C McC: Influence of sympathomimetic pressor drugs on arrhythmias caused by multiple stimuli. Circ Res 7:417-423, 1959

2. Moran NC, Moore JI, Holcomb AK, et al: Antagonism of adrenergically-induced cardiac arrhythmias by dichloroisoproterenol. J Pharmacol 136:327-335, 1962

3. Moore JI, Swain HH: Sensitization to ventricular fibrillation. I. Sensitization by a substituted propiophenone, U-0882. J Pharmacol 128:243-252, 1960

4. Dresel PE, MacCannell KL, Nickerson M: Cardiac arrhythmias induced by minimal doses of epinephrine in cyclopropane-anaesthetized dogs. Circ Res 8:948-955, 1960

5. Lucchesi BR, Hardman HF: The influence of dichloroisoproterenol (DCl) and related compounds upon ouabain and acetyistrophanthidin induced cardiac arrhythmias. J Pharmacol 132:372-381, 1961

6. Sekiya A, Vaughan Wiliams EM: The effects of pronetholol, dichloroisoprenaline and disopyramide on the toxicity to the heart of oubain and anesthetics. Brit J Pharmacol 21:462-472, 1963
7. Lucchesi BR: The action of nethalide upon experimentally induced cardiac arrhythmias. J Pharmacol 145: 286-291, 1964

8. Lucchesi BR, Whitsitt LS, Stickney JL: Antiarrhythmic effects of beta adrenergic blocking agents. Ann NY Acad Sci 139:940-951, 1967

9. Davis LD, Temte JV: Effects of propranolol on the transmembrane potentials of ventricular muscle and Purkinje fibers of the dog. Circ Res 22:661-677, 1968

10. Weidmann S: Effects of calcium ions and local anesthetics on electrical properties of Purkinje fibers. J Physiol (London) 129:568-589, 1955

11. Roynolds EW, MacDonald WJ, Greenfield BM, et al: Mechanisms of onset and termination of abnormal cardiac rhythm studied by constant monitoring. Amer Heart J 74:473-481, 1967

12. Lyon AF, DeGraff AC: Antiarrhythmic drugs. II. Clinical use of quinidine. Amer Heart J 69:834-837, 1965

13. Sokolow M, Edgar AL: Blood quinidine concentrations as a guide in the treatment of cardiac arrhythmias. Circulation 1:576-592, 1950 